\title{
Caracterização de novos isolados de Bacillus thuringiensis para o controle de importantes insetos-praga da agricultura
}

\author{
Emeline Boni Campanini ( $\left.{ }^{1 *}\right)$; Camila Chiaradia Davolos (2); Eliane Cristina da Cunha Alves ( $\left.{ }^{2}\right)$; \\ Manoel Victor Franco Lemos $\left({ }^{2}\right)$ \\ (') Universidade Federal de São Carlos (UFSCar), Rodovia Washington Luís, km 235, 13565-905 São Carlos (SP), Brasil. \\ (2) Universidade Estadual Paulista (UNESP), Via de Acesso Prof. Paulo Donato Castellane, s/n, 14884-900 Jaboticabal (SP), Brasil. \\ (*) Autora correspondente: emelinemeca@yahoo.com.br
}

Recebido: 2/nov./2011; Aceito: 10/set./2012

\begin{abstract}
Resumo
A bactéria Bacillus thuringiensis Berliner produz um corpo de inclusão paraesporal (cristal) de natureza proteica, formado durante a esporulação, que atua de forma eficiente no controle de insetos-praga de culturas economicamente importantes. Esse cristal é constituído de proteínas Cry, que são codificadas pelos genes cry; um isolado pode ser caracterizado pelo conteúdo de genes cry que apresenta. Visando caracterizar novos isolados no combate de insetos-praga pertencentes às ordens Lepidoptera e Coleoptera, 76 isolados bacterianos foram analisados molecularmente e tiveram seu potencial de controle avaliado por meio de bioensaios com larvas de Spodoptera frugiperda (J.E. Smith), Sphenophorus levis Vaurie e Tenebrio molitor Linnaeus. As análises moleculares indicaram 11 isolados (14,5\% da coleção), contendo genes lepidóptero-específicos e 17 $(22,37 \%)$ com genes coleóptero-específicos. As análises de patogenicidade revelaram dois isolados com alto potencial de controle para lagartas de S. frugiperda, um para larvas de S. levis e seis prejudiciais ao desenvolvimento das larvas de T. molitor. Esses isolados de B. thuringiensis podem ser promissores no controle biológico das referidas pragas.
\end{abstract}

Palavras-chave: controle biológico, genes cry, Spodoptera frugiperda, Sphenophorus levis, Tenebrio molitor.

\section{Characterization of new strains of Bacillus thuringiensis for the control of important insect pests in agriculture}

\begin{abstract}
Bacillus thuringiensis Berliner produces protein crystals that act effectively on the control of pests for several relevant crops. The cry genes codes for these proteins are named Cry proteins. The cry gene profile can potentially set each bacterial isolate as a potential pest control agent. Aiming to analyze new isolates for the controlling of pests belonging to the orders Lepidoptera and Coleoptera, 76 samples were molecularly analyzed and had their potential for control evaluated through bioassays with larvae of Spodoptera frugiperda (J.E. Smith), Sphenophorus levis Vaurie and Tenebrio molitor Linnaeus. Based on molecular analysis data, 11 samples (14.5\%) were able to control lepidopteran specific pests due to their cry genes content, and 17 samples (22.37\%) exhibited coleopteran specific cry genes. The bioassays results indicated two samples with highly effective against S. frugiperda, one against S. levis and six with high toxicity against T. molitor larvae development. The selected B. thuringiensis isolates may be promising for the biological control of these pests.
\end{abstract}

Key words: biological control, cry genes, Spodoptera frugiperda, Sphenophorus levis, Tenebrio molitor.

\section{INTRODUÇÃO}

O controle convencional de insetos-praga na agricultura, por meio de pulverizaçóes com inseticidas sintéticos, tem causado agressóes constantes ao meio ambiente, que se caracterizam principalmente pela contaminaçáo do solo e da água. Em adição, o uso abusivo desta prática tem favorecido a rápida seleçáo de insetos-praga resistentes, além de prejudicar os organismos não-alvo, visto que esse tipo de controle não é específico. Nesse contexto, uma alternativa pode ser o controle biológico, com destaque para o agente entomopatogênico Bacillus thuringiensis Berliner, 1911 (Eubacteriales: Bacillaceae). Este patógeno é amplamente recomendado por produzir toxinas específicas denominadas proteínas Cry, que têm atividade tóxica contra espécies pertencentes às ordens Lepidoptera, Coleoptera e Diptera, bem como às várias espécies de artrópodes, nematóides e platelmintos (Lereclus et al., 1993; van FrankenHUYZen, 2009).

A patogenicidade e a especificidade de isolados de $B$. thuringiensis são determinadas pelos tipos de genes 
cry funcionais existentes, uma vez que são estes genes que codificam as proteínas Cry (WANG et al., 2003). Assim, a determinação do conteúdo de genes cry de um isolado é de extrema importância, pois prediz o perfil de sua atividade tóxica e direciona os bioensaios (SAUKA et al., 2006), tornando possível avaliar o potencial de controle real exercido contra um inseto-alvo específico.

Entre as espécies que podem ser controladas por esse micro-organismo, estão insetos-praga de importantes culturas em todo o mundo, como Spodoptera frugiperda (J.E. Smith) (Lepidoptera: Noctuidae) na cultura do milho, Sphenophorus levis Vaurie (Coleoptera: Curculionidae) na cultura da cana-de-açúcar e Tenebrio molitor Linnaeus (Coleoptera: Tenebrionidae) em vários tipos de grãos armazenados (GAllo et al., 2002; Moreira et al., 2005). Tais culturas representam grande parte do que é consumido pela população, seja diretamente, como o arroz e o trigo, seja indiretamente, como o milho, utilizado também na alimentação animal pela agropecuária. A cana-de-açúcar, além da importância na alimentação, também possui importância por seu potencial como biocombustível. Portanto, manter bons índices de produtividade nessas culturas é de extrema importância e, neste contexto, mantê-las livres de insetos-praga torna-se fundamental.

A busca e a caracterização de novos isolados com potencialidades entomopatogênicas são fundamentais para o manejo da utilização de $B$. thuringiensis como agente de controle biológico, pois os isolados promissores podem ser empregados na produção de bioinseticidas mais eficazes, bem como na obtenção de genes cry com diferentes especificidades. Também é imprescindível o desenvolvimento de um banco de genes cry devidamente caracterizado, o que seria uma ferramenta importante para minimizar o aparecimento de possíveis resistências às proteínas Cry.

$\mathrm{O}$ presente trabalho objetivou estudar uma coleção de novos isolados de $B$. thuringiensis quanto ao perfil genes cry e a patogenicidade dos isolados positivos sobre três espécies de insetos de importância agrícola.

\section{MATERIAL E MÉTODOS}

\section{Linhagens bacterianas}

Foram analisados 76 isolados de B. thuringiensis, obtidos de amostras de solos de diferentes locais da cidade de Ilhabela, SP (231` $56^{\prime \prime} \mathrm{S}$; $\left.45^{\circ} 42^{\prime} 83^{\prime} \mathrm{O} \mathrm{O}\right)$. O isolamento das colônias bacterianas foi realizado utilizando-se 30 amostras de solo (um grama cada uma), coletadas durante os meses de outubro e novembro de 2005. O método de isolamento desenvolvido consistiu na adição de $10 \mathrm{~mL}$ de água Mili-Q estéril seguida de leve agitação e repouso por 1 hora, para que houvesse sedimentação da amostra. A solução foi filtrada com algodão, e o filtrado levado a $80{ }^{\circ} \mathrm{C}$ por 10 minutos, para eliminar possíveis micro-organismos náo esporulados. O filtrado foi diluído 10 e 100 vezes em água mili-Q autoclavada e as diluiçôes homogeneizadas, sendo $100 \mu \mathrm{L}$ de cada diluição submetido à inoculação em placas de Petri contendo meio NA (0,5\% extrato de levedura; $0,1 \%$ de triptona; $0,17 \mathrm{M} \mathrm{NaCl}$ e $0,15 \%$ de ágar bacteriológico).

A incubação foi feita em $\mathrm{BOD}$ a $30^{\circ} \mathrm{C}$ por 36 horas e as colônias obtidas foram avaliadas quanto à morfologia. As colônias selecionadas para as características correspondentes a bacilos foram visualizadas em microscópio de contraste de fase para a verificação da presença de esporos e cristais. Estas foram novamente submetidas à inoculaçáo em meio NA e incubadas a $30^{\circ} \mathrm{C}$ por cinco dias, para que houvesse a completa esporulação. Os isolados foram então estocados em fitas de papel filtro e armazenados em tubos criogênicos contendo $1 \mathrm{~mL}$ de solução de esporos $(1 \mathrm{~mL}$ água estéril + esporos da placa), sendo então mantidos a $10^{\circ} \mathrm{C}$.

Além destes, foram utilizadas três linhagens-padrão: B. thuringiensis var. kurstaki HD1 (lepidoptero-específica), $B$. thuringiensis var. tenebrionis (coleoptero-específica) e $B$. thuringiensis var. israelensis (diptero-específica), cedidas pelo Bacillus Genetics Stock Center (BGSC).

\section{Identificação dos genes cry por PCR}

Para a caracterização molecular dos genes cry 1 , as amostras do DNA genômico de cada isolado foram submetidas à amplificação com o oligonucleotídeo iniciador geral gral-cry1 (Bravo et al., 1998) e com 21 oligonucleotídeos iniciadores de subclasses cryl: crylAa, cry $1 A b, \operatorname{cry} 1 A c$, cry $1 A d$, cry $1 A e, \operatorname{cry} 1 A f$, cry $1 A g$, cry $1 B b$, $\operatorname{cry} 1 B c, \operatorname{cry} 1 B e, \operatorname{cry} 1 B f$, cry $1 C a$, cry $1 D a, c r y 1 E a, c r y 1 F a$ (Guidelli-Thuler et al., 2008), cry1Ba, cry1Bd, cry$1 \mathrm{Ga}$, crylIa, crylJa e crylKa (Guidelli-Thuler, com. pessoal - Tabela 1). Para a identificação de genes coleópteros-específicos foram utilizados os oligonucleotídeos iniciadores cry3Bb (Guidelli-Thuler, com. pessoal Tabela 1) e cry35Ba (Silva et al., 2010).

As reaçóes de amplificação foram feitas em volume de $20 \mathrm{~mL}$ contendo: $30 \mathrm{ng} / \mathrm{mL}$ de DNA molde, $250 \mathrm{mM}$ de uma solução de dNTPs (10 mM); 2,0 mM de $\mathrm{MgCl}_{2}$; 0,4 mM de cada iniciador; 1,0 U da enzima Taq DNA polimerase (Invitrogen); solução - tampão para a reação de PCR (1X) e água destilada Milli-Q previamente esterilizada (qsp $20 \mathrm{~mL}$ ). As condiçôes para realização das reaçóes de amplificação foram: 5 minutos a $95^{\circ} \mathrm{C}, 31$ ciclos consistindo de $1 \mathrm{~min}$ a $95^{\circ} \mathrm{C}$, temperatura de anelamento por 1 minuto a $72{ }^{\circ} \mathrm{C}$ e, um passo extra de extensão a $72{ }^{\circ} \mathrm{C}$ por 5 minutos. A temperatura de anelamento utilizada para cada par de oligonucleotídeos iniciadores foi a mesma indicada nos trabalhos de descrição, citados anteriormente. Os produtos de amplificação foram analisados em gel de agarose a 1,5\%, conforme SAMBrooK $_{\text {AMroo }}$ e Russel (2001). 
Tabela 1. Oligonucleotídeos iniciadores utilizados para amplificação dos genes cry

\begin{tabular}{|c|c|c|c|}
\hline Iniciadores & Sequências & Temperatura de anelamento $\left({ }^{\circ} \mathrm{C}\right)$ & Produtos esperados $(\mathrm{pb})$ \\
\hline \multirow{2}{*}{ cry1Ba } & 5' GCTATGACAGTCGCACTTATC C 3' & \multirow{2}{*}{50} & \multirow{2}{*}{820} \\
\hline & 5' АСТСTTATCGGTCCAAATCCAC 3' & & \\
\hline \multirow{2}{*}{ cry1Bd } & 5’ TAGGCGTGTGGGTGGTATTC 3’ & \multirow{2}{*}{50} & \multirow{2}{*}{522} \\
\hline & 5' АСАСТTСТGСТTСССАТTCTG 3' & & \\
\hline \multirow{2}{*}{ cry1Ga } & 5' TACTCAAGCAGCAAATCTACAC 3' & \multirow{2}{*}{44} & \multirow{2}{*}{817} \\
\hline & 5’ ACTGATGAATGGAGATGAGCG 3' & & \\
\hline \multirow{2}{*}{ cry 7 la } & 5' ATGTAGAGCCGTTTGTTAGTG 3' & \multirow{2}{*}{50} & \multirow{2}{*}{827} \\
\hline & 5' TATGGCAGAGAACGAAGGTG 3' & & \\
\hline \multirow{2}{*}{ cry1Ja } & 5' TTATCGGTTTATGTTCAAGCAG 3' & \multirow{2}{*}{51} & \multirow{2}{*}{729} \\
\hline & 5' TATTGTAGATGGCGGAGGTG 3' & & \\
\hline \multirow{2}{*}{ cry $1 \mathrm{Ka}$} & 5' CGCATTGAGGATAGCTTGTG 3' & \multirow{2}{*}{41} & \multirow{2}{*}{651} \\
\hline & 5' AGTTTCGGCAGTTGTCCCTC 3' & & \\
\hline \multirow{2}{*}{ Cry3Bb } & 5' TACGCAACAATACACTGACC 3' & \multirow{2}{*}{41} & \multirow{2}{*}{690} \\
\hline & 5' TCATCTGTTGTTTCTGGTGG 3' & & \\
\hline
\end{tabular}

\section{Criação dos insetos-praga}

As lagartas de $S$. frugiperda, provenientes da coleçáo do Laboratório de Ecologia Aplicada, do Departamento de Fitossanidade da UNESP, Jaboticabal, foram mantidas de acordo com o descrito por BARRETo et al. (1999). A mesma instituição também forneceu as larvas de T. molitor, as quais foram mantidas em potes plásticos de $500 \mathrm{~mL}$ de capacidade com tampa perfurada. Uma dieta pré-esterilizada ( $28,5 \mathrm{~g}$ de farelo de trigo $+1,5 \mathrm{~g}$ de levedura de cerveja) foi adicionada, de forma que a altura da coluna formada pela dieta fosse de aproximadamente $3 \mathrm{~cm}$ (De Bortoli et al., 2011). As larvas de S. levis foram cedidas pelo Centro de Tecnologia Canavieira (CTC-Piracicaba), onde foram criadas em dieta artificial semissólida desenvolvida e preparada pelo próprio instituto de pesquisa, de acordo com o descrito por Degaspari et al. (1987).

\section{Bioensaios}

O delineamento experimental inteiramente casualizado (DIC) constituiu-se de tratamentos compostos por suspensóes de esporo/cristal dos isolados positivos para os genes testados e por suspensóes de esporo/cristal das linhagens-padrão, utilizadas como controles positivos e negativos.

Para o preparo das suspensóes esporo/cristal, os isolados de B. thuringiensis e as linhagens-padrão foram submetidos à inoculação em placas de Petri, contendo nutriente Agar (NA) e incubados em B.O.D. a $30^{\circ} \mathrm{C}$ por 120 horas, para completa esporulação. Após esse período, todo o conteúdo bacteriano foi coletado, diluído em água contendo $0,05 \%$ de Tween-20 (espalhante adesivo) e quantificado por meio de leitura em câmara de Neubauer (BARreto et al., 1999). Suspensóes com concentraçóes iguais a $3 \times 10^{8}$ esporos por $\mathrm{mL}$ de Tween foram preparadas para a aplicação na superfície das dietas de $S$. frugiperda e T. molitor, e suspensóes com concentraçóes iguais a $3 \times 10^{7}$ esporos por $\mathrm{mL}$ de Tween foram incorporadas durante o preparo da dieta de S. levis; nesse caso, como seria necessário um volume muito maior das suspensões de esporos/cristais, a concentraçáo final precisou ser uma ordem de grandeza menor.

Para os testes com lagartas de $S$. frugiperda, cubos de dieta (com cerca de $5 \mathrm{~g}$ cada um) foram mergulhados na suspensão de esporos/cristais de cada linhagem testada, e, posteriormente, secos à temperatura ambiente por $30 \mathrm{mi}$ nutos em fluxo laminar. Para as larvas de T. molitor, cada $30 \mathrm{~g}$ de dieta foi umedecida em $30 \mathrm{~mL}$ de suspensão esporos/cristais. A dieta foi deixada em estufa a $50{ }^{\circ} \mathrm{C}$ até a completa secagem (cerca de 8 horas). Para S. levis, foram utilizadas alíquotas de $6 \mathrm{~mL}$ de dieta para cada larva. Durante o preparo, $6 \mathrm{~mL}$ de suspensão esporos/cristais foi adicionado a cada alíquota.

Lagartas de segundo ínstar de $S$. frugiperda foram ensaiadas em delineamento inteiramente casualizado, com 12 tratamentos e quatro repetiçóes (20 lagartas cada um). A mortalidade foi avaliada no sétimo dia após a exposição à dieta tratada. Como controle positivo, utilizou-se a linhagem-padrão $B$. thuringiensis var. kurstaki HD1 e como controle negativo a linhagem B. thuringiensis var. tenebrionis. Para as espécies $S$. levis e T. molitor, os bioensaios seguiram o mesmo delineamento experimental, com seis e vinte tratamentos respectivamente. Foram realizadas duas repetições, cada uma delas contendo 20 larvas de segundo ínstar das respectivas espécies. A avaliação da mortalidade de $S$. levis foi realizada 15 dias após a exposiçâo da larva à dieta tratada. Para T. molitor, avaliou-se o número de larvas, pupas e adultos, bem como a massa das larvas sobreviventes 30 dias após a instalação. Em ambos os bioensaios, foram utilizados como controle positivo a linhagem-padrão $B$. thuringiensis var. tenebrionis e como controle negativo $B$. thuringiensis var. israelensis. Nos bioensaios, com as três espécies de insetos, foi incluído um tratamento sem solução de esporos/cristais (testemunha).

Os bioensaios foram desenvolvidos em salas climatizadas $\left(\mathrm{T}=25^{\circ} \mathrm{C} \pm 2\right.$, U.R. $=70 \%$ e fotoperíodo $=14$ horas 
de luz: 10 horas de escuro). Os dados de porcentagem de mortalidade das larvas de $S$. frugiperda e $S$. levis, bem como a massa $(\mathrm{mg})$ das larvas sobreviventes da espécie $T$. molitor foram submetidos à análise de variância, utilizando o software Estat (FCA/UNESP de Jaboticabal), sendo as médias comparadas pelo teste de Tukey $(\mathrm{p}<0,01)$.

\section{RESULTADOS E DISCUSSÃO}

\section{Caracterização molecular}

A coleção de isolados foi analisada quanto à presença de genes cry reconhecidos por atuarem no controle biológico de insetos das ordens Lepidoptera e Coleoptera. Dentre os 24 genes cry estudados, 13 estiveram presentes nesta coleçáo de 76 isolados, sendo 22 isolados $(28,9 \%$ do total) positivos para pelo menos um tipo de gene $c r y$ (Tabela 2). Essa frequência pode ser considerada relativamente alta, uma vez que as amostras de solo são todas provenientes de uma mesma localidade (Ilha Bela, SP). Do total de isolados testados, nove $(11,8 \%)$ possuíam genes lepidóptero-específicos e 17 (22,4\%) possuíam genes coleóptero-específicos; os quatro isolados (IB5.3, IB8.1, IB9.2 e IB17.3) tinham simultaneamente genes específicos para o controle de insetos de ambas as ordens.

A maior porcentagem de amplificação foi verificada para o gene específico crylBf (nove isolados positivos), seguido dos genes crylDa, crylFa e crylla (oito isolados) e $\operatorname{cry} 1 B b$, cry $1 B e$ e cry $1 \mathrm{Ka}$ (sete isolados). Outros 11 genes da classe cryl testados (crylAa, crylAb, crylAc, cry $1 A$ e, cry $1 A f$, cry $1 A g$, cry $1 B a$, cry $1 C a$, cry $1 E a$, cry $1 G a \mathrm{e}$ cry $1 \mathrm{Ja}$ ) não estiveram presentes nos isolados desta coleção. A frequência total de genes lepidóptero-específicos $(11,8 \%)$ pode ser considerada baixa quando comparada às descritas em outros trabalhos como: 42,6\% (MoraEs e Capalbo, 1986), 54,0\% (Ferrandis et al., 1999) e 55,7\% (Guidelli-Thuler et al., 2008). No entanto, é importante ressaltar que nos trabalhos desses autores foram utilizados isolados provenientes de diversas localidades.

Em adição, essa coleção de isolados foi mais rica em genes da classe $c r y 1 B$ do que da classe $\operatorname{cry} 1 A$ (Tabela 2 ). Dentre as seis subclasses cry $1 B$ analisadas, cinco $(83,3 \%)$ estiveram presentes. E dentre as 10 subclasses cry $1 A$ estudadas, apenas uma ( $10 \%$ do total) esteve presente. Esses resultados sugerem que a presente coleção tem um perfil gênico diferente do normalmente observado, pois estudos como o de Bravo et al. (1998), Uribe et al. (2003) e Armengol et al. (2007), ao analisarem a presença de genes da subclasse cry 1 em isolados de B. thuringiensis utilizando oligonucleotídeos iniciadores (CERÓN et al., 1994; 1995), reportaram que os genes da subclasse cry $1 A$ foram muito mais frequentes que os da subclasse $\operatorname{cry} 1 B$.

Os isolados IB5.3, IB8.1 e IB9.2 exibiram o maior número de genes da subclasses cryl, com nove subclasses cada (Tabela 2), sem amplificação apenas para o gene

Tabela 2. Perfil gênico dos isolados de B. thuringiensis de Ilha Bela (SP)

\begin{tabular}{|c|c|c|c|c|c|c|c|c|c|c|c|c|c|}
\hline Isolados & $\begin{array}{l}\text { cry1- } \\
\text { geral }\end{array}$ & $\begin{array}{c}\text { cry } 1 \\
\text { Ad }\end{array}$ & $\begin{array}{c}\text { cry } 1 \\
B b\end{array}$ & $\begin{array}{c}\text { cry } 1 \\
\text { Bc }\end{array}$ & $\begin{array}{r}\text { cry1 } \\
\text { Bd }\end{array}$ & $\begin{array}{c}\text { cry1 } \\
\text { Be }\end{array}$ & $\begin{array}{c}\text { cry1 } \\
\text { Bf }\end{array}$ & $\begin{array}{c}\text { cry1 } \\
\text { Da }\end{array}$ & $\begin{array}{c}\text { cry } 1 \\
\mathrm{Fa}\end{array}$ & $\begin{array}{c}\text { cry } 1 \\
\text { la }\end{array}$ & $\begin{array}{c}\text { cry1 } \\
\mathrm{Ka}\end{array}$ & $\begin{array}{c}\text { cry3 } \\
B b\end{array}$ & $\begin{array}{c}\text { cry35 } \\
\mathrm{Ba}\end{array}$ \\
\hline IB1.2 & - & - & - & - & - & - & - & - & - & - & - & - & + \\
\hline IB3.2 & - & - & - & - & - & - & - & - & - & - & - & - & + \\
\hline IB3.3 & + & - & + & - & - & + & + & + & + & + & + & - & - \\
\hline IB4.1 & + & + & - & - & - & - & + & + & + & - & - & - & - \\
\hline IB5.3 & + & - & + & + & + & + & + & + & + & + & + & - & + \\
\hline IB8.1 & + & - & + & + & + & + & + & + & + & + & + & - & + \\
\hline IB8.2 & + & - & + & + & - & + & + & + & + & + & + & - & - \\
\hline IB9.2 & + & - & + & + & + & + & + & + & + & + & + & - & + \\
\hline IB10.2 & + & - & + & + & - & + & + & + & + & + & + & - & - \\
\hline IB13.2 & + & - & + & + & - & + & + & + & - & + & + & - & - \\
\hline IB17.3 & + & + & - & - & - & - & + & - & + & + & - & - & + \\
\hline IB17.4 & - & - & - & - & - & - & - & - & - & - & - & - & + \\
\hline IB20.1 & - & - & - & - & - & - & - & - & - & - & - & - & + \\
\hline IB20.3 & - & - & - & - & - & - & - & - & - & - & - & - & + \\
\hline IB21.1 & - & - & - & - & - & - & - & - & - & - & - & - & + \\
\hline IB24.1 & - & - & - & - & - & - & - & - & - & - & - & - & + \\
\hline IB25.1 & - & - & - & - & - & - & - & - & - & - & - & + & - \\
\hline IB26.2 & - & - & - & - & - & - & - & - & - & - & - & + & - \\
\hline IB29.2 & - & - & - & - & - & - & - & - & - & - & - & - & + \\
\hline IB30.1 & - & - & - & - & - & - & - & - & - & - & - & - & + \\
\hline IB30.2 & - & - & - & - & - & - & - & - & - & - & - & + & - \\
\hline Total & 9 & 2 & 7 & 6 & 3 & 7 & 9 & 8 & 8 & 8 & 7 & 3 & 14 \\
\hline
\end{tabular}

(+) Apresentou amplificaçấo para o gene; (-) nẫo apresentou amplificaçăo para o gene. 
cry 1 Ad. Esse resultado foi superior ao de Martinez e Caballero (2002), que constataram sete diferentes genes cry em um mesmo isolado, e inferior ao encontrado por Guidelli-Thuler et al. (2008), que notaram um isolado com 14 subclasses cry1. A grande variabilidade de genes cryl em um mesmo isolado é interessante, pois pode minimizar problemas relacionados à resistência aos bioinseticidas formulados à base de $B$. thuringiensis. No entanto, náo se deve descartar a possibilidade de que os iniciadores elaborados possam ter provocado a amplificaçáo de mais de uma subclasse, por serem gerados em uma regiāo de homologia entre elas, ocasionando assim um número superestimado de possíveis genes cry $1 \mathrm{em}$ alguns isolados.

Quanto à presença de genes coleóptero-específicos, três isolados $(3,95 \%)$ foram positivos para o gene cry $3 B b$ e 14 isolados $(18,42 \%)$ para o gene $c r y 35 B b$, totalizando 17 isolados distintos (22,37\% da coleção) (Tabela 2). Esses resultados foram semelhantes aos descritos por Bravo et al. (1998), em que $21,5 \%$ da coleção estudada continham genes codificadores de proteínas tóxicas a coleópteros. No entanto, em seu trabalho, os autores observaram genes lepidóptero-específicos em porcentagem muito maiores do que a de coleóptero-específicos, o oposto do que ocorreu nesse trabalho, cuja porcentagem de isolados coleóptero-específicos (22,37\%) foi ligeiramente maior em relaçáo aos lepidóptero-específicos $(11,8 \%)$. A presença de genes efetivos contra larvas pertencentes à ordem Coleoptera não é tão comum quanto à presença de genes efetivos contra a ordem Lepidoptera; em alguns trabalhos não se observou nenhum isolado portando genes codificadores de proteínas efetivas a larvas da ordem Coleoptera (ChaK et al., 1994; Ben-Dov et al., 1997). Esse resultado mais uma vez infere o perfil distinto dos isolados deste conjunto avaliado.

Variaçôes na distribuição e no conteúdo dos genes da classe cry 1 são comumente encontradas entre as diferentes coleçóes de $B$. thuringiensis estudadas em todo o mundo, o que sugere que as diferenças ecológicas do local

Tabela 3. Mortalidade média das lagartas de S. frugiperda submetidas aos tratamentos com isolados de B. thuringiensis com amplificação dos genes cry 1

\begin{tabular}{|lc|}
\hline Tratamentos & Mortalidade média (\%) \\
\hline IB17.3 & $85,00 \mathrm{a}$ \\
\hline IB8.2 & $80,00 \mathrm{ab}$ \\
\hline B. thuringiensis var. kurstaki - HD1 & $63,75 \mathrm{~cd}$ \\
\hline IB3.3 & $61,25 \mathrm{cde}$ \\
\hline IB10.2 & $61,25 \mathrm{cde}$ \\
\hline IB8.1 & $53,75 \mathrm{de}$ \\
\hline IB13.2 & $47,50 \mathrm{ef}$ \\
\hline IB9.2 & $38,75 \mathrm{f}$ \\
\hline IB4.1 & $36,25 \mathrm{f}$ \\
\hline IB5.3 & $33,75 \mathrm{f}$ \\
\hline B. thuringiensis var. tenebrionis & $3,75 \mathrm{~g}$ \\
\hline Testemunha & $2,50 \mathrm{~g}$ \\
\hline
\end{tabular}

CV $(\%)=10,97$. DMS $=13,8112$.

Médias seguidas de mesma letra náo diferem entre si pelo teste de Tukey a $1 \%$. de origem e/ou as relaçóes de coevolução estejam favorecendo a expressão de diferentes padrōes de genes cry 1 (Ferrandis et al., 1999). O perfil distinto de genes da classe $c r y 1$ verificado nesse trabalho reforça essa hipótese. Assim como observado dentro da classe cry 1 , as diferenças observadas para as frequências de genes cry entre as outras famílias de genes também são dependentes da fonte de origem e da área geográfica onde as amostras foram coletadas (Ben-Dov et al., 1997; Bravo et al., 1998).

A regiāo de Ilhabela (SP), de onde provêm as amostras de solo analisadas, é rica em insetos da ordem Diptera. Desde 1994, vem sendo realizado nessa localidade um programa de controle biológico de âmbito municipal, em parceria com a SUCEN (Superintendência de Controle de Endemias, SP), que utiliza a linhagem $B$. thuringiensis var. israelensis no combate de simulídeos, de acordo com o proposto por ARAújo-CoutinHo e LACEY (1990). Devido a esses fatores, a coleçáo de isolados aqui descrita foi anteriormente avaliada por CAMPANINI et al. (2012), utilizando-se três genes díptero-específicos, e apenas oito isolados foram positivos para esses genes. Em comparação, neste trabalho foram observados nove isolados lepidóptero-específicos e 17 coleóptero-específicos. Feitelson et al. (1992) mostraram que as espécies de insetos e linhagens de $B$. thuringiensis de uma mesma localidade vêm coevoluindo ao longo do tempo. No entanto, tais resultados sugerem que na regiáo de Ilhabela esse fato não está ocorrendo, uma vez que a regiáo é rica em insetos da ordem Diptera com um número muito maior de isolados com genes potenciais para o controle de insetos da ordem Coleoptera.

\section{Teste de patogenicidade}

A partir dos resultados moleculares, a patogenecidade dos nove isolados tiveram amplificação para os genes cryl e foram testados em lagartas de S. frugiperda, com intuito de promover a seleção dos mais eficientes no controle desse inseto-praga, bem como para verificar qual combinação gênica seria a responsável pela maior patogenecidade. A mortalidade foi analisada através de um teste de comparação de médias (Teste de Tukey), que agrupa resultados estatisticamente semelhantes em uma mesma classe. Foram geradas três classes distintas, sendo a classe que incluiu as maiores percentagens de mortalidade denominada como "alta eficiência", a que incluiu as menores porcentagens como "baixa eficiência" e a clase intermediária como "eficiência média".

Dentre os isolados testados, um (IB5.3) revelou baixa eficiência de controle, com mortalidade média de 33,75\% (Tabela 3); seis isolados (IB4.1, IB9.2, IB13.2, IB8.1, IB10.2 e IB3.3) tiveram médias de mortalidade entre $36,25 \%$ e $61,25 \%$, que foi considerada eficiência média, e dois isolados (IB8.2 e IB17.3) com médias de 
mortalidade acima de 75\%, considerada alta eficiência. Não houve relação entre a combinaçáo de genes $c r y 1$ específicos e o potencial de mortalidade de lagartas de $S$. frugiperda, pois os isolados IB5.3, IB8.1 e IB9.2, que continham a mesma combinação gênica, proporcionaram potenciais de controle significativamente diferentes: $33,75 \%$ (baixa eficiência), 53,75\% (eficiência média) e 38,75\% (eficiência média) respectivamente.

Nos bioensaios com larvas de $S$. levis feitos com os isolados cry3Bb positivos (B25.1, IB26.2 e IB30.2), verificou-se redução ou inatividade alimentar e a ausência de mudança de ínstar. As larvas perderam gradativamente a mobilidade e finalmente morreram devido à infecção generalizada, apresentando nesse ponto uma tonalidade escura. Esses sintomas corroboram os descritos por Habib e Andrade (1998) e Monnerat e Bravo (2000). Os resultados de mortalidade em $S$. levis também apresentaram três classes de combinaçôes (Tabela 4). O isolado IB26.2 foi altamente eficiente, com $76,66 \%$ de mortalidade. Os outros dois isolados, IB25.1 e IB30.2, tiveram mortalidade média de $53,33 \%$ e $63,33 \%$ respectivamente, sendo considerados como de eficiência média.

Para a análise de toxicidade às larvas de T. molitor, foram analisados 17 isolados positivos para os genes coleóptero-específicos (cry3Bb e cry35Ba). Embora os tratamentos não tenham ocasionado mortalidade das larvas, efeitos subletais foram observados. A linhagem-padrão $B$. thuringiensis var. tenebriones foi o tratamento que mais prejudicou o desenvolvimento das larvas, o que pode ser comprovado pela baixa massa média das larvas nesse tratamento (Tabela 5). Esse resultado já era esperado, visto que essa linhagem foi utilizada como controle positivo, por já ser amplamente caracterizada como capaz de controlar insetos da ordem Coleoptera.

Seis isolados testados (IB30.1, IB25.1, IB21.1, IB29.2, IB24,1 e IB26.2 - 7,9\% do conjunto) também reduziram a massa das larvas, revelando-se desfavoráveis ao desenvolvimento do inseto. Esse resultado foi superior ao obtido por SiLva et al. (2002), que constatararam apenas um isolado ( $1,2 \%$ da coleção daquele trabalho) eficiente contra T. molitor. Porém, os autores obtiveram a mortalidade das larvas de T. molitor, diferentemente do que ocorreu neste trabalho. Uma possível explicação para não se ter obtido a mortalidade das larvas é que talvez a suspensão de esporos/cristais não tenha aderido de forma adequada à dieta oferecida, a qual nesse caso consistia de farelo de trigo e levedura de cerveja e não de uma dieta em blocos sólidos como nos demais bioensaios, o que dificultou a adição das suspensôes. Os isolados IB9.2, IB17.4 e IB20.1 foram os menos prejudiciais ao desenvolvimento larval do inseto (Tabela 5), com médias semelhantes a da testemunha. Os demais isolados foram considerados intermediários.
Tabela 4. Mortalidade média de larvas de $S$. levis submetidas aos tratamentos com isolados de $B$. thuringiensis que amplificaram o gene cry $3 B b$

\begin{tabular}{lc}
\hline Tratamentos & Mortalidade média (\%) \\
\hline B. thuringiensis var. Tenebrionis & $86,66 \mathrm{a}$ \\
\hline IB26.2 & $76,66 \mathrm{ab}$ \\
\hline IB30.2 & $63,33 \mathrm{bc}$ \\
\hline IB25.1 & $53,33 \mathrm{C}$ \\
\hline B. thuringiensis var. israelensis & $13,33 \mathrm{~d}$ \\
\hline Testemunha & $3,33 \mathrm{~d}$ \\
CV (\%)=14,30. DMS $=19,3918$. & \\
Médias seguidas de mesma letra năo diferem entre si pelo teste de Tukey a 1\%.
\end{tabular}

Tabela 5. Massa média das larvas de T. molitor 30 dias após a aplicação dos tratamentos com os isolados positivos para os genes cry3 $3 b$ e cry35Ba

\begin{tabular}{|ll|}
\hline Tratamentos & Massa média (g) \\
\hline IB9.2 & $0,1265 \mathrm{a}$ \\
\hline IB17.4 & $0,1235 \mathrm{ab}$ \\
\hline IB20.1 & $0,1140 \mathrm{abc}$ \\
\hline Testemunha & $0,1109 \mathrm{abcd}$ \\
\hline IB20.3 & 0,1073 abcde \\
\hline IB18.1 & 0,0899 abcdef \\
\hline IB1.2 & 0,0800 abcdef \\
\hline IB17.3 & 0,0785 bcdef \\
\hline IB30.2 & $0,0766 \mathrm{bcdef}$ \\
\hline B. thuringiensis var. israelensis & $0,0757 \mathrm{cdefg}$ \\
\hline IB5.3 & $0,0705 \mathrm{cdefg}$ \\
\hline IB3.2 & $0,0655 \mathrm{defg}$ \\
\hline IB8.1 & $0,0633 \mathrm{efg}$ \\
\hline IB26.2 & $0,0527 \mathrm{fg}$ \\
\hline IB24.1 & $0,0493 \mathrm{fg}$ \\
\hline IB29.2 & $0,0481 \mathrm{fg}$ \\
\hline IB21.1 & $0,0476 \mathrm{fg}$ \\
\hline IB25.1 & $0,0471 \mathrm{fg}$ \\
\hline IB30.1 & $0,0437 \mathrm{fg}$ \\
\hline B. thuringiensis var. tenebrionis & $0,0289 \mathrm{~g}$ \\
\hline CV $(\%)=15,60$. DMS=0,0472. & \\
\hline Médias seguidas de mesma letra nâo diferem entre si pelo teste de Tukey a $1 \%$. \\
\hline
\end{tabular}

\section{CONCLUSÃO}

A coleção de isolados oriundos de Ilha Bela possui um perfil diferente dos já descritos na literatura, com mais isolados contendo genes coleóptero-específicos do que lepidóptero-específicos. Nesta última classe são encontrados mais genes da subclasse $\operatorname{cry} 1 B$ do que da subclasse $\operatorname{cry} 1 A$.

Os isolados IB17.3 e IB8.2 são altamente eficientes no controle de lagartas de $S$. frugiperda. O isolado IB26.2 é o mais eficiente no controle de larvas de $S$. levis. Os isolados IB30.1, IB25.1, IB21.1, IB29.2, IB24,1 e IB26.2 afetam negativamente o desenvolvimento das larvas de T. molitor.

Esses isolados de $B$. thuringiensis são promissores e podem ser incorporados em programas regionais de manejo integrado de pragas das ordens Lepidoptera e Coleoptera. 


\section{REFERÊNCIAS}

ARAÚJO-COUTINHO, C.J.P.C.; LACEY, L. Controle de simulídeos com concentrado emulsionável de Bacillus thuringiensis. Boletin de la Oficina Sanitaria Panamericana, v.108, p.213-219, 1990.

ARMENGOL, G.; ESCOBAR, M.C.; MALDONADO, M.E; ORDUZ, S. Diversity of Colombian strains of Bacillus thuringiensis with insecticidal activity against dipteran and lepidopteran insects. Journal of Applied Microbiology, v.102, p.77-88, 2007.

BARRETO, M.R.; LOGUERCIO, L.L.; VALICENTE, F.H.; PAIVA, E. Insecticidal activity of culture supernatants from Bacillus thuringiensis Berliner strains against Spodoptera frugiperda (J.E. Smith) larvae. Annual Society Entomology, v.28, p.675-685, 1999.

BEN-DOV, E., ZARITSKY, A., DAHAN, E. Extended screening by PCR for seven $c r y$-group genes from field-collected strains of Bacillus thuringiensis. Applied and Environmental Microbiology, v.63, p.4883-4890, 1997.

BRAVO, A.; SARABIA, S.; LOPEZ, L.; ABARCA, C.; ORTIZ, A.; ORTIZ, M.; LINA, L.; VILLALOBOS, F.J.; PEÑA, G.; NUNEEZ-VALDEZ, M.E.; SOBERÓN, M; QUINTERO, R. Characterization of cry genes in a mexican Bacillus thuringiensis strain collection. Applied and Environmental Microbiology, v.64, p.4965-4972, 1998.

CAMPANINI, E.B.; DAVOLOS, C.C; ALVES, E.C.C.; LEMOS, M.V.F. Isolation of Bacillus thuringiensis strains that contain Dipteran-specific cry genes from Ilhabela (São Paulo, Brazil) soil samples. Brazilian Journal of Biology, v.72, p.1-5, 2012.

CERÓN, J.; COVARRUBIAS, L.; QUINTERO, R.; ORTIZ, A.; ORTIZ, M.; ARANDA, E.; LINA, L.; BRAVO, A. PCR analysis of the cryI insecticidal crystal family genes from Bacillus thuringiensis. Applied and Environmental Microbiology, v.60, p.353-356, 1994.

CERÓN, J.; ORTIZ, A.; QUINTERO, R.; GÜERECA, L.; BRAVO, A. Specific PCR primers to identify cryI and cryIII genes within a Bacillus thuringiensis strain collection. Applied and Environmental Microbiology, v.61, p.3826-3831, 1995.

CHAK, K.F.; CHOW, C.D.; TSENG, M.Y.; KAO, S.S.; TUAN, S.J.; FENG, T.Y. Determination and distribution of cry-type genes of Bacillus thuringiensis isolates from Taiwan. Applied and Environmental Microbiology, v.60, p.2415-2420, 1994.

DE BORTOLI, S. A.; VACARI, A. M.; POMARI, A. F.; VEIGA, A. C. P.; VOLPE, H. X. L.; MAGALHĀES, G. O.; MAEDA, J. M. Produção de insetos: da base à biofábrica. In: BUSOLI, A. C.; FRAGA, D. F.; SANTOS, L. C.; ALENCAR, J. R. D. C.; GRIGOLLI, J. F. J.; JANINI, J. C.; SOUZA, L. A.; VIANA, M. A.; FUNICHELLO, M. Tópicos em Entomologia Agrícola IV. Jaboticabal: Gráfica e Editora Multipress, 2011. p.95-116.

DEGASPARI, N.; BOTELHO, P.; ALMEIDA, L.C.; CASTILHO, H.J. Biologia de Sphenophorus levis Vaurie, 1978 (Col: Curculionidae) em dieta artificial e no campo. Pesquisa Agropecuária Brasileira, v.22, p.553-558, 1987.

FEITELSON, J.S.; PAYNE, J. ; KIM, L. Bacillus thuringiensis: insects and beyond. BioTechnology, v.10, p.271-176, 1992.
FERRANDIS, M.D.; JUÁREZ-PÉREZ, V.M.; FRUTOS, R.; BEL, Y.; FERRÉ, J. Distribuition of cryI, cryII and cryV genes within Bacillus thuringiensis isolates from Spain. Systematic and Applied Microbiology, v.22, p.179-185, 1999.

van FRANKENHUYZEN, K. Insecticidal activity of Bacillus thuringiensis crystal proteins. Journal of Invertebrate Pathology, v.101, p.1-16, 2009.

GALLO, D.; NAKANO, O.; SILVEIRA NETO, S.; CARVALHO, R.P.L.; BAPTISTA, G.C.; BERTI-FILHO, E.; PARRA, J.R.P.; ZUCCHI, R.A.; ALVES, S.B.; VENDRAMIM, J.D.; MARCHINI, L.C.; LOPES, J.R.S.; OMOTO, C. Entomologia Agrícola. Piracicaba: Fundação de Estudos Agrários Luiz de Queiroz - FEALQ, 2002. 920p.

GUIDELLI-THULER, A.M.; SENA, J.A.D.; ABREU, I.L.; DAVOLOS, C.C.; ALVES, S.B.; POLANCZYK, R.A.; VALICENTE, F.H.; LEMOS, M.V.F. Bacillus thuringiensis: diversidade gênica em isolados Lepidoptera-específicos. Arquivos do Instituto Biológico, v.75, p.411-420, 2008.

HABIB, M.E.M.; ANDRADE, C.F.S. Bactérias entomopatogênicas In :ALVES, S.B. (Ed.). Controle microbiano de insetos. Piracicaba: FEALQ, 1998. cap.12, p.383-446.

KUO, W.; LIN, J.; TZENG, C.; KAO, S.; CHAK, K. Cloning of two new cry genes from Bacillus thuringiensis subsp. wuhanensis strain. Current Microbiology, v.40, p.227-232, 1999.

LERECLUS, D.; DELÉCLUSE, A.; LECADET, M.M. Diversity of Bacillus thuringiensis toxins and genes. In: ENTWISTLE, P.F; CORY, J.S.; BAILEY, M.J.; HIGGS, S. (Ed.). Bacillus thuringiensis, an environmental biopesticide: theory and practice. Chichester: John Wiley, 1993. p.37-69.

MARTINEZ, C.; CABALLERO, P. Contents of cry genes and insecticidal toxicity of Bacillus thuringiensis strains from terrestrial and aquatic habitats. Journal of Applied Microbiology, v.92, p.745$752,2002$.

MONNERAT, R.G.; BRAVO, A. Proteínas bioinseticidas produzidas pela bactéria Bacillus thuringiensis: modo de ação e resistência. In: MELO, I.S.; AZEVEDO, J.L. (Ed.). Controle biológico. Jaguariúna: Embrapa Meio Ambiente, 2000. p.163-200.

MORAES, I.O.; CAPALBO, D.M.F. Produção de bactérias entomopatogênicas. In: ALVES, S. B. (Ed.). Controle Microbiano de Insetos. Piracicaba: Manole, 1986. p.297-310.

MOREIRA, M.A.B.; ZARBIN, P.H.G.; CORACINI, M.D.A. Feromônios associados aos coleópteros-praga de produtos armazenados. Química Nova, v.28, p.472-477, 2005.

SAMBROOK, J.; RUSSEL, D.W. Molecular Clonning: A Laboratory Manual. 3. ${ }^{\text {rd }}$ Edition. Woodbury, New York EUA: Cold Spring Harbor Laboratory Press, 2001. 2344p.

SAUKA, D.H.; COZZI, J.G.; BENINTENDE, G.B. Detection and identification of cry1I genes in Bacillus thuringiensis using polymerase chain reaction and restriction fragment length polymorphism analysis. Current Microbiology, v.52, p.60-63, 2006. 
SILVA, S.F.; DIAS, J.M.C.S.; MONNERAT, R.G. Isolamento, identificação e caracterização entomopatogênica de bacilos de diferentes regiôes do Brasil. Brasília: Embrapa Cenargen, 2002. 4p. (Embrapa Comunicado Técnico,70)

SILVA, N.; GUIDELLI-THULER,A.M.;ABREU, I.L.; DAVOLOS, C.C.; POLANCZYK, R.A.; LEMOS, M.V.F. Characterization and selection of Bacillus thuringiensis isolates effective against Sitophilus oryzae. Scientia Agricola, v.67, p.472-478, 2010.
URIBE, D.; MARTINEZ, W.; CERÓN, J. Distribution and diversity of cry genes in native strains of Bacillus thuringiensis obtained from different ecosystems from Colombia. Journal of Invertebrate Pathology, v.82, p.119-127, 2003.

WANG, J.; BOETS, A.; VAN RIE, J. Characterization of cry 1 , cry 2 and cry 9 genes in Bacillus thuringiensis isolates from China. Journal of Invertebrates Pathology, v.82, p.6371,2003 